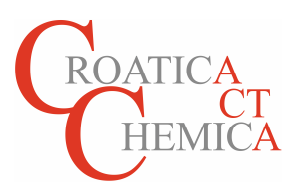

\title{
Chemistry 4.0
}

\section{Challenges and Solutions for the Digital Transformation}

\author{
Jan von Knop
}

\author{
University of Düsseldorf, D-4000 Düsseldorf, Germany \\ Author's e-mail address: Jan.Knop@uni-duesseldorf.de \\ RECEIVED: December 15, 2016 * ACCEPTED: December 20, 2016
}

Essay is dedicated to Professor Nenad Trinajstic on the occasion of his $80^{\text {th }}$ birthday. It is based on the invited talk delivered on the first day of the MATH/CHEM/COMP 2016 Conference, held in Dubrovnik from June $20^{\text {th }}$ to $25^{\text {th }}$. The first day was dedicated to Nenad Trinajstić, one of the founders of MATH/CHEM/COMP conferences, on the occasion of his $80^{\text {th }}$ birthday.

$\mathbf{L}$ ET me first thank the Organizing Committee, especially Professor Hrvoj Vančik, for the invitation to give a talk in the main session of the MATH/CHEM/COMP 2016 Conference, dedicated to my colleague and friend Professor Nenad Trinajstić. The privilege to speak today is still greater than 20 years ago when I was invited to speak on a scientific meeting dedicated to $60^{\text {th }}$ birthday and $35^{\text {th }}$ anniversary of Nenad's scientific work. Today we celebrate the fifty-fifth anniversary of the outstanding scientific life of Nenad Trinajstić.

I will start my essay with the following anecdote: My University honors every year an outstanding person from German society with the Heinrich Heine Professorship, which lasts one year. Our first Heinrich Heine Professorship holder was Marcel Reich-Ranicki (Born Wloclawek, 1920 died in Frankfurt, 2013), one of the most famous German literary critics, who luckily escaped as a young man the holocaust in Warsaw. At his first lecture, he asked the students: Dear students, what do you think about what is a literary reviewer speaking, when he reviews a book of a famous writer? It was so silent overcrowded auditorium with more than 1000 students, that you could hear a needle falling. Then finally Marcel Reich-Ranicki said "He will talk about himself". So this anecdote may give you an idea about whom I am going to talk today.
I would like to start with some words about my scientific cooperation with my colleague and outstanding researcher Professor Nenad Trinajstić, one of the pioneers of the modern mathematical chemistry and applied graph theory. Our cooperation started with our first publication in Tetrahedron in 1972 (L. Klasinc, E. Pop, N. Trinajstić, and J. von Knop, Theoretical Studies of Positional Isomers Obtained by Annelation of Benzene and 5-Membered Ring Heterocyclics Containing Nitrogen, Oxygen, or Sulphur, Tetrahedron 1972, 28, 3465-3474.) and continued until 2004 with a paper in Chemical Modelling: Applications and Theory (D. Babić, D. J. Klein, J. von Knop, and N. Trinajstić, Combinatorial Enumeration in Chemistry, in: Chemical Modelling: Application and Theory, Edited by Alan Hinchliffe, The Royal Society of Chemistry, London, 2004, Vol. 3, pp. 126-170.).

During these 32 years of our cooperation, we published altogether 87 papers and reviews in scientific journals and two books. They covered topics from theoretical chemistry, computational chemistry, various applications of graph theory and computer science. During this period Nenad was more than 50 times as the visiting professor involved in research and teaching at the University of Düsseldorf. He spent there more than two years of his life. During his stays in Düsseldorf, we had hundreds of

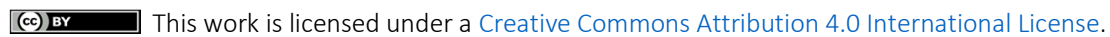


interdisciplinary meetings and conferences with colleagues from chemistry, biology, physics and mathematics. He had a remarkable influence on the research in Düsseldorf. According to the Science Citation Index Nenad Trinajstić was for many years the mostly cited scientist of the University of Düsseldorf - a very impressive fact. I personally and my colleagues from the University of Düsseldorf are very thankful to Nenad, for his continuous cooperation and support. He kept me in touch with applied graph theory and computational chemistry - a part of science my heart was beating for.

My University gave me salary for doing something else. I was in charge of the Computing Center of the University and was teaching computer science. My main research fields in computer science were Networking and Computer Security. In my third life, after retiring from the University, I am working in journalism. I am editor-in-chief of a publishing house with a portfolio of twenty-four periodicals and journals covering IT-security, economy and human resources.

I will end this part with another anecdote, which will be the last in this essay. I am presenting this anecdote because only close colleagues may know that Nenad Trinajstić, besides being a respectable scientist, is also interested in mathematical structure of poems and novels and used to be a decent poetry writer. For example, Nenad, in collaboration with a notable Croatian poet Boro Pavlović (Požega, 1922 - Duga Resa, 2001), investigated whether or not the principles of symmetry and asymmetry operate in literature. Professor Istvan Hargittai (Budapest, 1944) has known about this research and invited them to prepare an article on their work for the special issue of the journal Computers \& Mathematics with Applications. They prepared the article entitled On Symmetry and Asymmetry in Literature that appeared in Comp. Math. Appl. 1986, 12B, 197-227. Later Hargittai prepared a book entitled Symmetry - Unifying Human Understanding (Pergampon Press, New York, 1986, pp. 1-1045.) that contained articles from the special issue of the journal. The last poem Nenad wrote was Grave in Turopolje, written on November $5^{\text {th }}, 2007$, after the funeral of Mateo Katulić (Zagreb, 1984 - Volosko, 2007), his grandson who died suddenly a few days earlier on November $2^{\text {nd }}$.

During one of Nenad's first visits in Düsseldorf, my university was struggling with question whether it should be renamed from the University of Düsseldorf into the Heinrich Heine University, after the name of the famous poet Heinrich Heine which was born in Düsseldorf in 1797 (died 1856 in Paris). There was a nasty discussion with unfriendly comments in the daily newspapers whether the university is at all worth to be renamed after Heinrich Heine. And I think I remember correctly that in one of our interdisciplinary circles Nenad raised the point, the poem
Loreley of Heinrich Heine is about a rock on the Rhine, where a wonderful fair lady named Loreley was singing. This poem happens to be Heine's most successful poem. Nenad said that Loreley, is one of the dozens rocks on the Rhine between Koblenz and Boppard which all look like one another. This rock is only famous because Heine wrote his poem about it. And now every year thousands of tourists, even from as far as Japan are visiting Loreley to see this rock. Then he finished, with the following: Gentlemen, - he said - Düsseldorf is only known by some people outside Germany, but Heinrich Heine knows everybody. So what is the university struggling about? It fits perfect. A middleclass university with the first-class branding. A wonderful argument, don't you agree?

Now I am going to briefly discuss about my research in the computer science. My research, which I presented in Zagreb 20 years ago were characterized with the following title: The Information Superhighway. From Vision to Reality? My main question was: Can machines think? It is really difficult to imagine that 20 years ago the hardest thing for computers was the simple stuff, they could play chess, a game of mechanical rules and finite options. But recognizing a face, recognizing a joke or driving a car was another matter. Until few years ago, we could not imagine that drones would be used to deliver and advertise products, three dimensional printing would allow increased product customization, data glasses would be used for virtual shopping, and information would be stored in a cloud. This new dimension of inventing computing machines and computer controlled networks in our daily life, the forth revolution, called Digital Revolution, has opened up new opportunities to boost the economy and empower customers as never before. Access to information and content is potentially on offer at anytime, anywhere and on any device.

My report about Chemistry 4.0. will manly not be concerned with science but with economy of science, although science and research a playing an eminent important part, I will start with the following questions that have to be raised:

- How important is the digital transformation for chemistry?

- What must be done?

- Who are the winners?

I will try to respond with the following three theses:

1. The digital transformation of industry is creating tremendous opportunities for Europe and confronting it with huge challenges

The possibilities opened up by connected, more efficient production and novel business models are highly promising, yet the risks are equally dramatic. According to research by Roland Berger consultants, Europe could by 
2025 , in the period of ten years, see its manufacturing industry add gross value worth 1.25 trillion euros - or suffer the loss of 605 billion euros in foregone value added.

2. The digital transformation of industry is also driving a radical structural transition in Europe`s economies

New data, connectivity, automation and the digital costumer interfaces are challenging the existing value chains. Companies must take a long, hard look at their products and skill sets. And they have to improve their digital maturity if they are to recognize new opportunities, develop suitable offerings and get them to market quickly.

\section{The digital transformation of industry demands con-} certed action within Europe

The regulatory framework must be harmonized, with a new weight given to relevant issues. At the same time, a powerful, no-gaps information and communications infrastructure is needed if European industry is to remain competitive. As standards are shaping our digital future, companies and governments need to get engaged seriously in their global definition.

These trends are not to be compared simply with greater level of production automation, a process that has, since the 1970s, been driven by developments in electronics and information technology. The widespread adoption by manufacturing industry around the world of information and communication technology is now pawning the way for disruptive approaches to development, production and the entire logistic chain. This networking within an "internet of things, services, data and people" will transform the future of manufacturing. The term Industry 4.0 is used to refer to a fourth industrial revolution.

May I just shortly recall what Industry 4.0, or the fourth revolution in the industry, stands for? The first revolution began at the end of $18^{\text {th }}$ century with the introducing of water- and steam-power into industrial manufacturing. The first mechanical loom was invented in 1784. The second revolution started at the beginning of the $20^{\text {th }}$ century with the establishment of machine tools industry and a phase of rapid industrialization mass with electrical power. The third revolution at the early $70 \mathrm{~s}$ in $20^{\text {th }}$ century was characterized by the change of mechanical and analog electronic technology to digital electronics and the use of information technology for automatization of the industrial production. Finally, the fourth industrial revolution is the current trend of automation and data exchange in manufacturing technologies. It includes cyber-physical systems, the internet of things and cloud technologies. It creates, what is currently called a smart factory. The term Industry 4.0 refers to a further development stage in the organization and management of the entire value chain process involved in manufacturing industry. The concept of Industry 4.0 is widely used across Europe, particularly in Germany's manufacturing sector and also USA and the English-speaking world.

I would like to address the actual progress in industry and Chemistry 4.0 that can be seen at the moment when it comes to cyber-physical-systems, smart products and cloud computing. The impressions that could be seen, for example, at this year Hannover Fair are split. On one hand we could see exciting approaches on human-machine collaboration. The struggle about the German robot manufacturer Kuka, which Chinese try to buy, is an actual example for the race which started. On the other hand, many companies have not accepted the challenge 4.0 yet. They still offer traditional products and just put new labels on them. A great skepsis was noticed concerning abstract future scenarios and cloud computing. Chemical industry was a forerunner in automatization during the last century, but it remains very conservative in the present. The difficulties are best seen in BASF which is with the revenue of 70 billion euro in 2015 the world leader of the chemical industry. BASF in under high pressure of China and has to react on the takeovers, like Syngenta (seeds) in Switzerland and to the overcapacity of the USA and Chinese competitors who offer cheap basic products. Furthermore, BASF had, for example, to close the production of propylene from natural gas in the USA, due to lower prices of oil. And the BASF value added chain from oil in Siberia to vitamins is much too broad. Change management in direction of specializing or rebuilding the manufacture chain is not in sight at BASF. Competitors already concentrate on basic chemicals.

So what are the main driving forces and challenges in Chemistry 4.0?

- Raw material change

- Energiewende and use of surplus electricity

- Digitalization and connectivity across the value chain

Ensuring the supply of raw materials at reasonable prices represents one of the greatest challenges for the chemical industry in the $21^{\text {st }}$ century. Due to ever increasing population growth and the demand for raw materials in emerging countries in Asia, there will be shortages in the raw material supply in short term and they will be more expensive in long term. What actions are seen?

- Intensive fundamental research in the field of material conversion for improving existing and creating new value chains are necessary. 
- New large-scale usable technique for producing hydrogen without automatic yielding carbon dioxide.

- Transfer of research results to new economically and ecologically sustainable products and technologies.

With more solar and wind energy being produced, sustainable electricity supply in Northwest Europe is constantly increasing. This can offer great opportunities for the chemical industry! The supply of sustainable energy can bring reduction in energy costs, but it can also offer numerous new, high-value products. New business cases and platforms have to be developing for using electricity in chemical processes or for chemical transformation via hydrogen. Already today, for example, in Germany the chemical industry is greatest consumer of electrical energy with $10 \%$ of the total use, which may rise even more.

The future topics could be:

- Inorganic electrochemistry (Chlorine production a.o.)

- Organic electrochemistry

- Plasma and microwave driven processes.

In all countries of our world, traditional manufacturing industry is in the throes of a digital transformation that is accelerated by exponentially growing technologies, for example, intelligent robots, autonomous drones and sensors, as already said. Companies and their industrial processes need to adapt to this rapid change if they are not to be left behind the developments in their sector and by their competitors.

What are the challenges on the way to Chemistry 4.0? First of all there are some overall goals:

- Improving operational effectiveness

- Reducing unscheduled downtime

- Driving higher returns of investment

All three are well known classical items. But there are also some new ones IT-challenges:

- Big data analytics

- Cyber security

- Intellectual property rights

- Data protection

- High investments

There will also be a high impact on the work environment:

- Need for qualifications

- Technology acceptance

- Digital natives with high expectations, inside and outsides the company, can be found everywhere
Next are:

\section{The legal implications}

Law has always followed significant changes in mind and culture. Our era is no exception. In the digital age, the integration of customers and business partners is generating completely new business models and new models of cooperation. Legal issues and question of liability and protection of intellectual property are becoming increasingly important. International business is for companies without qualified legal support today impossible. The bookshelves of law literature in libraries and the number law offices practicing IT-law are growing significantly. In my modestly-sized city of Düsseldorf (with the population of roughly 520.000), we have already more than 300 law offices practicing IT-law.

\section{Standardization}

Digital transformation presents a new set of challenges that require novel approaches to integrate new technologies including internet of things, cloud computing, cyber security and big data. The role of standards is a key in supporting Europe to make the digital shift. But there are still many questions open, what standards and standardization solutions are missing to complete the digital shift.

So what needs to be done now? Let me start with Companies.

Europe's companies have a good chance of benefiting from the digital transformation. To do so, however, they must put a series of conditions in place and up the tempo of change.

Top management must focus its strategy on achieving digital maturity. Digitalization is a job that belongs on the boss's desk.

Middle management now has the opportunity to prove that it can deal with the new challenges and develop distinctive new business models.

Experts should foster a digital culture and pay more attention to the incremental and disruptive possibilities opened by digital developments.

Technicians - including those in IT departments - must be further enabled to the digital future.

Customers and suppliers should familiarize themselves with the opportunities afforded by digital economy and learn to see them as potential assets.

What needs to be done by the Governments?

\section{Competitiveness}

Europe's governments can play an important part in helping European industry to become more competitive. In many areas, companies on the old continent 
already lag a long way behind their US rivals, to some extend because the US has resolutely promoted many elements of the digital future. An example is Apple who developed every one of the most important technology in his smart products, including iPhone and iPad with state funding.

\section{Balanced regulatory framework}

A regulatory framework is needed that allows Europe's diversity and its industrial capabilities to be translated into competitive advantages. It is also important to coordinate European activities and speak with one voice when representing Europe's common interests on the international stage. A harmonized, balanced and genuinely pan-European single digital market is needed in order to overcome current fragmentation. Huge gains in efficiency could, for example, be realized by consolidating the telecommunication market. By way of comparison, Europe has fifty-five separate mobile networks, while the US has just five. The future legal framework must guarantee technology neutrality and support the use of the most efficient technologies.

Harmonized Data Protection for the EU

On May $24^{\text {th }} 2016$, the EU-directive for data protection entered in to force and it shall apply from May $25^{\text {th }}$, 2018. The objective of this new set of rules is to give citizens back control over their personal data, and to simplify the regulatory environment for business. The 28 EU member states have to transpose it into their national law by May $6^{\text {th }}, 2018$. Companies, doing business in EU, have not to deal any more with 28 different national data protection laws, but with one European law which ensures a high standard of protection.

Triggering investment in the digital future

To date, Europe has invested far too little in the digital future. In the US, venture capital equivalent to about 17.5 billion euros is channeled into this field every year - against a meager 3.5 billion for the whole Europe. This figure is not a result of shortage of capital. General conditions for investors are missing.

\section{Business alliances}

Flagship project must be realized as governments, the business communities and scientific institutes move in concert toward the digital transformation. A cross-industry European economic alliance should encourage clusters and supports the development of skills and networking effects. It should be more then wanting to rank as equals with the big US internet players and rivals from China, Korea and Taiwan. It is all about translating Europe's diversity into a competitive advantage.
There are currently three political events with great consequences.

The first is the Transatlantic Trade Investment Partnership (TTIP)

The discussion of global business alliances cannot be complete without mentioning the trade agreement referred to as the Transatlantic Trade and Investment Partnership that the European Union and the United States are currently negotiating. It aims to reduce trade barriers on goods and services in a wide range of sectors. Most of the negotiations are centered on reducing regulatory barriers to trade, safety, environment, data protection and financial security and measures protecting the rights of investors.

Civil society in both, European Union and US, have raised various concerns about the TTIP. There have been large protests across Europe. I cannot go further into the details about the concerns, but I would just like to say that if the TTIP agreement fails, both, Europe and US will be the loosers. May be Asia and Russia will be the winners. The pragmatic way would be, to accept the disadvantages and take the best out of the TTIP.

The second is Brexit.

Another point which highly concerns our industry is the referendum that Britain hold on Wednesday, June $23^{\text {rd }}$, 2016, on leaving the European Union. A process often referred to us as Brexit. Those who favored leaving argue that the European Union has changed enormously over decades with regard to the size and the ever-increasing bureaucracy, diminishing British influence and sovereignty. Those who wanted to stay said that a medium-size island needs to be part of a large block of likeminded countries to have real influence and security in the world, and leaving EU would be costly. The arguments of both blocks were understandable and within limits correct. But most economists argue that a Brexit will hurt Britain and weaken also the European Union and the industry of both.

And lastly a Qualification initiative is necessary.

Digitalization will create new jobs, but it will also eliminate old ones - mostly unskilled ones. We have seen that in every structural transition to date. If the net balance is to add more jobs, we must concern ourselves with qualifications. Our goal must be to take people with us on our journey by providing them with training and development - a great challenge for the European University System.

In conclusion, I want stress the following points:

The digital transformation presents huge opportunities to 
European industry. The cumulative value added potential for the European industry over the next ten years is estimated to 1.25 trillion euros. This value creates potential for the chemical industry in Europe roughly 25 billion euros per year. So what is necessary to reach the goals?

Suggestion is to seize opportunities, change structures and join forces!

The chemical industry must join the digital journey now. This will help to
- achieve feedstock flexibility

- build operational intelligence

- achieve further intensification and modularization

- translate costumer's need into application better and fasten then ever.

I end my essay with the following concluding words:

Chemistry 4.0 requires a new mindset - still a long way to go. To reach the targets a strong support from Universities and Research Organizations is needed. 